\title{
The art of workplace learning
}

\section{Padma Ramsamy-Prat}

The research develops the cases of two young professionals working at the communication department at the Conservatoire National des Arts et Metiers, Cnam in Paris. The focus is placed on their learning practices at work and description of their subjective experiences. Although the results show some similarities in the learning process, there are nevertheless other characteristics that appear behind the scene. Indeed, their actions tend to show individuals performing an art where strategies and tactics (de Certeau, 1990) are carried out. Moreover, the need to learn about the job conveys a positive image of the individuals who appear pleasant and helpful. Besides, space used for learning becomes a space for creativity, intelligence and art.

Keywords: workplace learning, art, strategies, interpersonal communication

\section{The art of workplace learning}

This article presents two cases at the Conservatoire National des Arts et Metiers, Cnam University in Paris. Two young professionals working at the communication department agreed to take pictures of their learning practices at work and comment them later at their convenience. My interest in practice-based learning relies on real situations which enable to examine similarities, differences and challenges in the learning process. These situations develop understanding on how learning processes participate in the activity of workers. In the present situation, learning follows a requirement because new tasks appear at work. The practice encourages new ways of doing things in daily routines. The two individuals are junior communication specialists and they need to know about researchers and their research activities in order to inform the other institutions in the university. They claim to have a lot to learn in order to perform their task. Communicating about research is essential as it aims at informing the staff and the general public about the activities of the 
institution. Sharing with the general public represents a means of attracting private institutions and companies for future research projects and funding. Therefore, the difficulty of the task is to promote research using communication skills and techniques to describe research activities in simple, common language. In this paper, I examine what I am calling the art of workplace learning and how it is embedded in strategies used by practitioners. At the same time, the learning processes convey a positive cooperative professional image in producing professional knowledge.

The research investigates on their learning process. How do they learn at work? Are there self-regulated learning involved? What gestures are displayed in the learning process? The first article introduces theories of learning, and focuses on workplace learning. I will then present the methodology and the findings along with the limitations of the study.

\section{Formal vs informal learning}

Formal learning starts at school where we qualify for a certain profession. In most schools and universities, specialization is offered before entering the labour market in an attempt to be operational immediately. In these cases, learning is acknowledged; it is formal and intentional. In the company, formal learning takes place when staff training is offered as a human resource policy of development. Contrary to what Littlejohn \& al. (2016) suggest, in France training is well accepted and considered effective.

Learning at work can be explicitly informal learning because being on the workplace means carrying out different tasks. Informal learning depends on the individual, mainly his interest, motivation and self-satisfaction. Those characteristics may influence self-regulation and organization of learning depending on time allotted to other activities. Other characteristics must be taken into account, the selfengagement towards the job and the company, or even the goals set for a future job inside or outside the company. Consequently, the worker invests his time and energy to cover his intentions, mostly through deutero (self) learning. Deutero learning is developed by action science (Argyris \& al. 1987) and contributes to lifelong learning. He may even acquire some competencies in the learning process, which can be suitable for other actions. For instance, knowing how to proceed when in need of writing a memo is beneficial, not only to the worker, but also to the team, or the division. Besides, the worker can share with a colleague, allowing both parties to learn.

Therefore, it may account for the fact that if learning is organized in an intentional manner, it may not be entirely informal. Learning is considered as an 
expected activity. However, learning how to do things contributes greatly to the organisation. In many ways, learning at work is specific.

\section{Learning at work is specific}

Learning at work has a strong historical past. In craftsmanship, workers have always started the learning on the workplace where the senior worker known as a professional, would act as a mentor to the junior. The French have developed the "Compagnonnage" but it has existed in various forms all over the world and has proved to be very successful. The modern version is called apprenticeship and is offered in most professions. Organized mentorship is commonplace in many companies. Team learning can be initiated as well. I investigated on an original form of team learning on the clients' premises in software companies where the client's project allows a junior to learn while doing. Unexpectedly, the junior was not the only learner as the clients benefited also from the experiment (Ramsamy-Prat, 2014).

Competition and poor labour market have influenced the way we learn. We put forward other knowledge that is required by organizations in order to remain employable. What makes the difference between two qualified candidates are behavioural abilities and adaptability to change (Baraille, 2010: 7). Indeed, behavioural abilities offer the guarantee to work efficiently with others whereas adaptability provides the necessary flexibility. Behavioural competencies are a means of covering uncertainty and dysfunctions in organizations (Baraille, 2010).

The reasons why learning at work is specific are numerous. The first one stems from the everyday tasks required (Littlejohn $\&$ al. 2016) and interactions with others (Mayen, 2002). Asking information or confirmation from a colleague represents the casual everyday on-site learning and is largely admitted in many professions. Also, the authors put forward that professional learning is intertwined with the job itself, and prioritizing becomes part of self-regulating knowledge (Billet, 2004). The latter argues that, in addition, the resources provided by the work situation takes part in the learning (Billet, 2010: 4). Nonetheless, if it turns out that learning and working are embedded, the possibility to distinguish one activity from the other may represent a challenge (Argyris \& Schön, 1992). 


\section{Developing creativity in space}

In the learning process, the environment offers ground for creativity. The need to learn in order to perform a task requires competencies in communication skills for two reasons. First, information is obtained through communication with others. The second reason relies on the ability to create and maintain good relationships with others, which I call relational knowledge (Ramsamy-Prat, 2015). For example, when in need to learn about the job, individuals drive to convey a positive image and appear pleasant and helpful. Therefore, space used for learning becomes a space for creativity, intelligence and art. In vocational training, space can be a key factor; it is designed as part of the training programme (Agamben, 2007). Training professionals use financial and creative means- colours, music, and furniture- to make it more attractive, far from tensions and daily work space. Bourgeois and Nizet (1999) claim training space is protected, which encourage individuals to engage in the learning process. I would add that space is manipulated at will. This accounts for the fact that working space is used as learning space. Besides, creativity tends to shadow the learning and brightens behind the scene as a performance (Goffman, 1973). Indeed, professionals' actions tend to show individuals performing an art where strategies and tactics (de Certeau, 1990) are carried out.

\section{Strategies and tactics}

The "Practice of Everyday Life» express how the individual referred as the consumer applies creativity so as to benefit from them. The author shows how we design daily activities applying procedures with "schemes of operation and technical manipulations" (de Certeau, 1990: 71). He differentiates two major techniques used as an art of doing: strategies and tactics. Strategies appear inside organizational power structures, whereas tactics are set up by subjects who are subjugated. Strategies are deployed against external relations to reach official or proper ends whereas tactics show defensive and opportunistic means. The latter is used in limited ways but seizes the moment. If strategies rely on a proper environment, tactics make an environment which they can penetrate (de Certeau, 1990: 59). This form of intelligence of the moment has been called cunning intelligence in the study of Greek mêtis which was deployed in times of wars (Detienne \& Vernant, 1974). The workplace becomes a privileged place of observation for the researcher who can perceive an art of doing, knowledge and skills.

Strategies and tactics put forward an art of doing but also an art of saying. 


\section{Learning and gestures}

The body expresses gestures. In interactions, they are addressed to the other, and are seen, heard and perceived. They accompany discourse, and they expose themselves in gestured discourse that carries a complementary communicative function. They are referred to as embodied interactions. Let's consider verbal gestures and nonverbal ones.

\section{Non-verbal gestures}

Non-verbal gestures carry a co verbal function because they encourage better understanding of speech. In this study, the two communication professionals use speech, eye, hand and pointing gestures aiming at questioning and understanding their peers and the researchers of the institution. These gestures offer a plural language "as a mediation between thought and speech" argues Calbris (2003). It reminds a co text which provides what Alin (2010) refers to as a symbolic enunciation. Symbolic enunciation accounts for the meaning which is at stake in professional practice. The author adds other gestures express technical enunciations that aim at explaining their objectives. In the study, reading, inquiring and writing being at the heart of the practice represent trade gestures (Jorro, 2006, 2016). As for professional gestures, they tend to shoot in a rigorous manner, at a precise time and are subjective. While making the distinction between trade and professional gestures, the author claims that gestures exhibit knowledge and knowledge in action. When describing gestures in everyday life, Mauss (1950:117) considers the correspondence between the specific gesture and the result of activity. $\mathrm{He}$ also underlines that out of the need to express, the body is considered as a tool, a toolobject that individuals displace at their convenience.

\section{Speech gestures}

Gestures using discursive activity attempt to convey a message addressed to the other. The gesture operates on interpersonal communication which is interactive and relies on physical presence (Cros; Meyer, 2014). Although speech gestures are often embedded with other body gestures, it brings clarification and active communication and allows the other person to respond. In interactions, speech gestures offer the possibility to repeat, clarify, argue, convince or deny. Speech gestures enable conversations and these conversations can be analysed (Kerbrat-Orecchioni, 2005) 
for further understanding. When added to other body gestures, speech is one but essential clue of meaning in interactions. In learning acts, body gestures are often adjusted to speech, thus presenting multi modal communication (Filliettaz, Bronckart, 2005; Mondada 2005, 2016). The speech is coded and purposeful.

In the following data, I will show how gestures and particularly enunciation is analysed. Beforehand, I will explain the method carried out.

\section{Method}

A qualitative method was designed for the inquiry. I met four persons from the research division of the Cnam, two of them accepted to be part of the study. In this experience, the methodology relied on photographs taken by the protagonists themselves. The pictures added to the study for two reasons. First, they helped to recall the activity after action because professionals tend to forget how they perform tasks. Second, it contributed to better interviewing; I used them to focus on the actual activity. Further agreement was to comment on them; I opted for a qualitative method of inquiry designed by Vermersch $(1994,2011)$. Micro phenomenological interviewing is a method interested in the experience of actions. The psychologist develops the concept of experiential fulfilment to drive the subject to his/her experience at that moment since the situation is decontextualized. The information provided by the interviewee creates awareness and offers access to implicit and subjective experience. It allows identifying some data concerning decision-making and strategies developed by the subject in the present activity. It constitutes a facilitating tool to access verbalization. The pictures enabled to bring back verbalization to the actual situation and avoid what Vermersch calls satellite information. In micro phenomenological interviewing, the researcher's guidance is an essential part of the tool. Consequently, my voice was soft, I adopted a low tone, paused very often to help focus on a precise action.

An individual meeting at their office was facilitated to explain the methodology and request some pictures of their learning situations at work. Talking about learning at work arises many questions; people tend to think they work in the workplace and make a clear distinction between spaces: learning is at school, working in the office. Consequently, I did not provide any explanations about learning situations or precisions as an attempt to avoid influencing the practitioners. I believe that the choice of learning situations to be personal as they represent crucial elements of genuine interaction and construction of meaning for the subject.

This method allowed flexibility in timing because it has become difficult to obtain the participation of busy workers who claim they cannot make time for experiments. In addition, the experiment enables the worker to think of himself as a 
learner in certain situations. This element creates awareness on the learning process itself, but also on times when performing a task requires the need to learn. Therefore, it takes the worker some reflection on what learning is and when learning is necessary to challenge the required task.

\section{Pictures framed}

Phase1. A 30-minute meeting was arranged with four workers, at the office to explain the study and obtain their participation. Two of them volunteered. We agreed on a month period to take the photos and email them. I name the interviewees Danielle (woman) and Joe (man). Both in their early thirties, they confide this is their second job after their studies. Danielle made sure each picture she sent came with an explanation. Joe waited for our interview to express about them. They both sent four pictures. I collected three pictures and one selfie for Danielle; four pictures for Joe.

Phase 2. We adopted email communication to plan an individual interview at their office. We agreed to inquire about their choices and obtain explanations for an hour. Micro-phenomenological interviewing (Vermersh, 1994, 2011) allows the researcher to keep a backward and non-influential position. The pictures were used as a support to contextualization and helped in viewing the practitioner in action. The interview transcripts are put into English and analysed. Semiotic analysis (Filliettaz, Bronckart 2005; Kerbrat-Orecchioni, 2005; Mondada 2005, 2016) is performed in numerous rounds in an attempt to make analogies and differentiations between the two cases.

Phase3. The interview took place at the office. In both cases, someone popped in and we were disturbed. But learning and an art of learning was noticeable. Although the interview was expected, this event was not. Actually, because of the activity, unexpected ethnographic observation took place following an actual dual intertwined situation: the interview and the work. Both workers took the time to answer a colleague enquiring about work. In itself, this situation represents a learning case which can be stated as: how to stop work, answer a co-worker and get back to work. In other words, learn to accept being disturbed, and perhaps either waste some time in the process or distribute time differently. I was then able to observe an everyday practice and the ways of operating of both professionals. 


\section{Two interviewees}

Danielle and Joe are both in charge of communication. Joe lists all research projects, describes them, give all details for application. He emails the projects to all the institutions, the head of laboratories and doctoral students. A scientific classification offers a quick view of all projects and their duration. He provides verbal and numerical information about all projects, and assists in administrative applications. Danielle reads and investigates about research, sums up the projects and rewrites for the staff and the general public in a magazine called the Cnam Mag, she works also on external communication.

The following section describes the results of the study and offers grounds for discussion.

\section{Results and discussion}

"So, I learn by myself, and then I learn with others...for the Website, I worked a lot with a colleague..." (Danielle)

"then...by myself...we learn from one another..." (Joe)

Four main gestures stem from the experiment: reading, inquiring, participating and performing. For example, reading: I learn by myself and inquiring: then I learn with others. Learning about new research projects seems compulsory. Not only are they new to the job, but both must understand new projects in various scientific fields in order to communicate about them. Participating in presentations add to their understanding, sometimes a direct contact with the researcher allows a few clarifying questions. Performing follows the line of trial and error, which enables corrective actions during the process.

\section{Learning examples}

Deutero learning

Deutero learning (Argyris \& al. 1987) is said to contribute to lifelong learning. Both Joe and Danielle learned from a previous job and are applying the previous learnings in their current job. The data provides some material on behaviour at work. In her previous job, Danielle worked in a publishing company and had to read and write 
about authors and their stories. According to her, at the Cnam, mentioning figures is essential. Joe specialises in computing and worked in a software company before Cnam.

"Already, I must talk figures, at Cnam it's 80.000 auditors, research means 260 doctoral students... I've learned to shut my mouth and accept sometimes to get an earful..." (Danielle).

"I've learned different things...I've learned to work better and also fast because of deadlines..." (Joe)

Both share their knowledge transfer about reading documents and putting data on line. Moreover, they adopt a step by step approach in inquiring and writing activities:

"First, I write different paragraphs, I make a draft, and then I put the paragraphs together, after I read" (Danielle)

"I call or email the researcher, I take notes, then I put things in order, I design before putting on line" (Joe)

This step by step process corresponds to lifelong learning as they both apply the process when performing the writing activity.

\section{A duet}

'No, you can't do that...it won't work...have you tried.... Then you must use URL..." (Joe)

This is what I overheard during the interview with Joe, a colleague knocked, greeted me and shared about a problem to access a piece of information he needs. This example provides the understanding on how interaction is essential in learning, it enables to readily solve problems and gain time. Learning situations in interaction with others is clearly announced by Danielle:

“... I work a lot with Stephanie M...who is in charge of communication...I learn from her..." (Danielle) 
It raises another question though, did the colleague ask Joe because he assumed Joe knew the answer, or does Joe carry the image of the helpful person. In other words is Joe considered competent or helpful? What follows entitles to think there may be a little of both.

\section{Reflection and transferability}

This activity offers grounds for self-regulated learning. Reflection on action allows leaning on trial and error processes to carry out a task. In interaction, one could argue that each practitioner plays the role of the trainer for each other. This improvised trainer is available and handy, co-construction of solutions lead to problem-solving.

The pictures helped to focus on the activity being carried out. With this support, retrospection of actions can be observed. Calbris (2003) points out that if gestures pave the way to speech, it means it is the expression of a pre conceptualized scheme. As for Vermersch $(1994,2011)$ when viewing a film, the focus is placed on actions being carried out. An individual cannot correct the testimony of the subjective experience because it is impossible to claim it has not been or describe the subjective experience. The subject only can claim accessing his experience and formulate it to others.

Danielle learned to organize "My thesis in 30 seconds" event while doing with her counterpart. Similarly, for digital communication a form of supervision was set up until she feels autonomous. The assumption is that she will add knowledge from what she was taught.

"...here I am in digital communication, I worked a lot with a colleague, but now, through repetition, I do more and more by myself..."

The added knowledge stands as background knowledge she acquired in her previous position. Background competencies reinforce learning processes and give way to new ways of problem-setting and problem-solving. Both interviewees stated in different ways how they apply the competence of transferability to learn to perform in a new job.

“...I studied at university ...this is a great help in learning” (Danielle)

“...I already knew how to do this...I apply it here...” (Joe) 


\section{Characteristics for learning}

\section{Self-interest and curiosity}

"With this person, I listen, with others I just hear...Voila." (Danielle)

In learning, interest and motivation are acknowledged factors. The learning motive is put forward to render the positive image of the speaker. This situation shows some similarity to what happens in class: some students work/understand better with some teachers/trainers. The reasons do not always appear clearly. Both Joe and Danielle put forward their curiosity in the learning process; they both have to inquire and inform about the research projects in all fields. They claim their curiosity and selfinterest help them in this task. Regarding semiotic analysis voilà ends a sentence (Filliettaz, Bronckart 2005; Kerbrat-Orecchioni, 2005). Danielle states the difference between listening and hearing. The ending accounts for the explanation, there's only one: it is relevant to this person. Had it been another person, she would have been hearing: Voilà. The affective motive is put forward; they both are the same age and share the same experience at work. They belong to the same community as I will explain later.

\section{Time}

One could argue that when this formal learning is planned, then time no longer becomes a challenge. The fact that learning and doing, and learning while doing seems so difficult to separate are also that professionals cannot admit they spend time on the learning. Besides, once the work is performed, they do not take or have the time to reflect on the learning. This aspect limits learning since many tasks await the worker at his desk. When Danielle realised she was spending too much time on writing the articles for the Cnam Mag research magazine, she convinced her boss to sign up in a writing class. The calculations she made about time represented the arguments she produced in the interpersonal communication with her boss (Cros, Meyer, 2014). She expected the class to be effective.

“...2 hours for writing an article instead of $3 \ldots 10$ minutes to read instead of $60 \ldots ”($ Danielle)

Moreover, learning benefits other actions when the learner applies the same learning style or method: 
“...now the lesson I learn when I read an article on a topic I don't know...I do the same..." (Joe)

\section{Creativity}

Although the learning described look ordinary, the results show that the creativity of ordinary people in everyday life glitters. As stated previously, a colleague popped in during the interview. In Danielle's case, a woman stepped in to ask about a file. In Joe's office, a man questioned about a case by the door. I will attempt to analyse each act step by step. According to Alin (2010), an act presents four characteristics: it is enacted by an individual and is addressed, designs what has been performed, remains, leaves its mark and contributes to transform the social world.

The act is carried out in a performance where the backstage character appears on stage, in the light of the other protagonists and claim audience. What makes me think of performance as Goffman $(1973,1974)$ would describe is the presence of the researcher. I become the witness and audience of the unexpected. Referring to Mauss (1950: 117), I try to consider the correspondence between the specific gesture and the result of activity. During the interaction with the newcomer, the silent and subtle tricks- looking, smiling, using a soft voice- performed appeared efficient (de Certeau, 1990). The protagonists rely on those tricks to obtain the information they need to carry on with work. The soft voice is performed by the smiling woman:

"Do you mind if..."

The subtle proper manner and asking permission are not genuine. The colleague does not allow time for the answer, and asks the question nonetheless. The protagonist relies on tricks covered with a smile and soft voice to obtain the necessary information. I could argue that this could have waited, but maybe Danielle's positive image is at stake. If a colleague needs help, she must act professionally, particularly when there is an audience, here the researcher.

"Sorry to interrupt, but ..."

This sentence is addressed to both of us. Politeness covers the act of interrupting my interview with Joe; the gentleman greets me and addresses his colleague. Goffman $(1973,1974)$ refers to rituals individuals perform in everyday life which is part of living and using codes in society. Joe's positive image appears important as he 
detains some information or knowledge that he will pass to someone else. Then, he seems competent, but also helpful. His act may stand for a tactic as expressed below.

\section{Greek metis}

During both interviews, a colleague disturbed us. I focus on the art of learning in reference to Mauss (1950: 117) who points out the specific gesture and the result of activity. In addition, considering Greek metis which is practical intelligence (Detienne, Vernant, 1974) or tactic (de Certeau, 1990), anticipation about a future need is at stake. In workplace learning, strategies and tactics represent a significant part of the learning and can be a resource for lifelong learning

"...for My thesis in 180 seconds...I had to work with Stephanie M, who is in charge of Communication at the $\mathrm{ComUE}^{7}$. Anyway, the event was organized within ComUE...then I had to work with her...And, it appears that I got along well with her, so we talked a lot about our job...I need to learn, so I am more interested... With this person, I listen, with others I just hear...Voila."

When the ordinary hero (de Certeau, 1990) moves the learning space with him, he needs are appropriation of the other's text. The art of performing combines the art of speech and learning. The latter could represent useful gestures in lifelong learning; they are adjusting gestures (Jorro \& al, 2016). The listening gesture represents an adjusting gesture for it is adaptable to the situation the strategy the practitioner relies on is to talk and show interest:

"I need to learn, so I am more interested..."

\section{A space invented}

Moreover, the practical intelligence proves even more useful when the space changes. Danielle has to work with Stephanie M., and meeting are arranged at the latter's office, or on the spot of the event "My thesis in 30 seconds". In both cases, the space is a new. The change of space appear as a benefit to the learning. The space, itself, participates to the learning and contributes to the learning. The space stands for a space of activity (Barbier; Galatanu, 2004). The subjects create the

${ }^{7}$ ComUE : in France, Community of Universities 
space for the learning activity. When Danielle goes to Stephanie's office for work, she uses the space to learn about how to organize the event. Similarly, when preparing "My thesis in 30 seconds" event, she takes the opportunity to learn about the research projects the doctoral students are working on. The same applies to Joe, when inquiring about the research grants, he learns about them from the specialist in order to answer some general questions when required.

"...the learning, it's because I am in contact with the doctoral students..." (Danielle)

“...it's N.L. who works in bio-computing on Quid6...I asked and I learned about it" (Joe)

\section{Positive image and professional identity}

It is acknowledged that when questioned on their jobs, professionals tend to show a positive image. Speech gestures create scenarios to promote professional identity. Referring to situated learning developed in 1990s by Lave and Wenger, I observe contextual learning is used to promote identity and create meaning. For example, the learners appear motivated when expressing about document reading. In formal and informal encounters, gestures rely on strategies to demonstrate expertise as an attempt to promote professional image. The team collects knowledge as the beginner becomes active and immersed in the social community. The learner depends on the relationship to change role, he moves on as he connects the learning to identity expression. He becomes mature and collaborates when sharing the purposeful information linked to his identity.

Semiotic analysis ((Filliettaz, Bronckart 2005; Mondada 2005, 2016) shows how boosting positive image cover dynamism, motivation, work load or professionalism. The utterance regarding those items aim at restoring a misrepresentation: people also work hard at university and are dynamic even if they are civil servants (a lifeposition). Speech gesture reinforces the strategy deployed by the protagonist. Conversation analysis (Kerbrat-Orecchioni, 2005) shows calculated wording and high intonations. The following enunciations illustrate:

- Dynamism, motivation and work load:

"I need to learn, so I am motivated (Danielle) 
People here leave the office at 5, I sometimes stay much longer...I prefer to finish the task" (Joe)

Both interviewees claim they do not want a classic office job; they work as people do in the private sector, thus underlining motivation and professionalism. A professional thinks that work needs to be done and respects deadlines.

- Intelligence:

"I know what virtual screening is" (Joe)

"I can also speak about an emergency case at SNCF (the French railways) or explain migratory flow in Kesovo" (Danielle)

The verbs know/speak/explain may sound doubtful, but carry the intention of showing intelligence and willingness to learn.

- Competency:

Danielle commented each photograph sent:

"When I agree on something, I do it right...I am a perfectionist...When you claim you're a communication pro, you don't throw a picture just like that..."

The example serves as an illustration to express competency. The dynamic tone accompanies the adjective perfectionist. Each sentence carries the claimed competency: do it right, perfectionist, pro. The anaphoric form represents the strategy and the researcher can hear.

- Ambition

"The best website is the CNRS (French national scientific centre)...it's perfect..." (Danielle)

Does she aim at a similar result? Later, she admits taking inspiration from the CNRS website. 
- Professional advice

"It would be a mistake not to carry out next year..." (Danielle)

"Other scientists obtain grants I don't see why not in humanities" (Joe)

The verbatim show how in situated learning, the learner becomes an expert and takes advantage to share his knowledge with his peers.

The verbatim show how in situated learning, the learner becomes an expert and takes advantage to share his knowledge with his peers.

Community and learning

What Danielle enounced about her counterpart is striking:

“...it turns out we get along well, so we talked a lot about work...we have the same profile, approximately the same age...so she becomes a girlfriend...a professional relation, but in an amicable way..." (Danielle)

The age factor creates identification of the same needs and same language. A form of bond between the two women in the same jobs has contributed to a sense of belonging to the same community. Besides, the subjective experience might be fake or incomplete; the second part of the sentence was not readily stated. The guidance leads to explore her experience not in describing it but towards its goals (Vermersch, 1994, 2011): so she becomes a girlfriend.

I can argue that in Joe's case, there may be the idea of only helping out a "friend" but I will discuss another option later. Let's underline the fact that the new generation has started to co-work more readily. In a previous study on pharmacists, the younger practitioners showed a strong desire to work with other medical professionals whereas senior pharmacists displayed some resistance (Ramsamy-Prat, 2015).

\section{Professional identity in action}

When the interview was interrupted, another striking event took place. Joe answered his colleague, but soon after dashed to the door and talked to him. The intonation was very audible: it was high enough to be heard by everyone. It was clear he forgot to deliver a piece of information, but was close enough (I could hear the colleague 
muttering). This performance reminds the need of learning to be acknowledged and valued by both the environment and management. I noticed later that the middle manager's office was close, so were his colleagues, on the same floor. As a result, because of the visible activity, the helping act appears also as a profitable tactic: the boss witnesses the act. Joe "performs" his professional identity while assisting the colleague because this action can be valued.

As for the argument about time for learning, a learning limit may be calculated if the benefits are not valued. Danielle comments on the "My thesis in 30 seconds" with some pride:

"...it was a real success, yes. No, well really it was a success (smiles then laughs)... Well, we had positive feedback...from all the personnel... Well, so this year, we'll do this again...this time it's a pleasure...it's stimulating."

Later during the interview,

“...I worked a lot with my colleague, and then, through repetition...I can do things by myself..."

\section{Conclusion and discussion}

This research analysed practised-based learning of two individuals in the communication department at university. It focused on how people think and say they learn through subjective experience. Both individuals reported good selfregulated learning as a dynamic that would contribute to lifelong learning. Moreover, they put forward the high interest in their job that adds to the dynamic and interest in learning. They pay attention to "getting the job done in a good way" to demonstrate their professional identity. Semiotic analysis and observation of the unexpected interruptions complete their subjective experience where strategies and tactics imply professionalism. The need for recognition action appears clearly in the unexpected interaction with a colleague.

I would like to point out that if there is a strategy behind the learning, therefore intentionality is calculated, so it's not informal, it is organized learning. What appears creative though is the space that the learner carries with him and uses at will. According to theorists, self-regulated learning at work relies on motivation, cognitive and metacognitive processes and how they interact during learning. As for researchers, the motivation to learn remains a stable factor. One could add the opportunity that is seized, in other words, the tactic behind learning. 
Besides strategies, tactics and community, one may consider the position of the learners. Being juniors, it may appear that there is no alternative but to learn with and from others. Their junior position does not provide the authority to postpone or refuse sharing information with other colleagues. In other words, the acceptance of learning comes with the willingness to keep the job. In most organizations, cooperation at work is required.

In relational knowledge, I underline the anthropological question related to giving and giving back (Ramsamy-Prat, 2015) and it was not studied in the two cases. Self-interest and motivation drive to paying attention and giving but the agents learn to reciprocate which enable to pursue the relationship. A big part of the motivation in learning concerns professional identity. Indeed, learning and progressing augments the identity of the person. This cannot be fulfilled if there is no recognition from management. A tension may be observed between personal implication in learning and the need for recognition. It may account for the strategy using performance in an attempt to become visible to the audience.

It would be worth investigating on how the two individuals think of the learning process after the experiment. Has there been any change in their behaviours? Has it contributed to more access to learning and which forms in particular? One may assume they have paid more attention to self-regulated learning for a while. The investigation could be longitudinal.

Two learners cannot provide a lot of data; the results could encourage enlarging the number of cases and including both juniors and seniors in the process. The photographic data is interesting as it is easily accessible, flexible, non-intrusive and can be applied to most professions. The picture represents a support for spontaneous responses; it facilitates access to embodied gestures and is specific to a situation even if the activity belongs to a category of daily activities. Moreover, a photograph can stand on a desk as a reminder for further learning opportunities or recalling past learning experience. It may allow comparisons with learning situations in positive and negative outcomes.

This will need further longitudinal investigation. This study shows its limitations relying on a sample in only one department. This approach could be extended to other professionals in different contexts. It aims at designing a programme where subjective experiences participate to capitalize and optimize individual and collective knowledge. 


\section{References}

Alin, C. (2010). La geste formation. Gestes professionnels et analyse des pratiques. Paris: L'Harmattan

Argyris, C.; Putnam, R.; Mac Lain Smith, D. (1987). Action science. San Francisco: Jossey Bass

Argyris, C.; Schön, D. (1992). On organizational learning. Cambridge: Blackwell

Baraille, O. (2010). Les apprentissages professionnels informels. Paris: L'Harmattan

Barbier, J.M.; Galatanu, O. (2004). Les savoirs d'action. Une mise en mot des compétences. Paris: L'Harmattan

Billett, S. (2004). Learning through work. Workplace participatory practices pp. 109-125 in Rainbird, H., Fuller, A., Munro, A. (eds.) Workplace Learning in Context. London: Routledge.

Billett, S. (2010). Learning through practice. Heidelberg: Springer

Bourgeois, E.; Nizet, J. (1999). Apprentissage et formation des adultes. Paris: PUF

Calbris, G. (2003). L'expression de la pensée d'un homme politique. Paris: Ed. CNRS

Cros, F.; Meyer, C. (2014). La communication interpersonnelle en formation. Usages, effets et enjeux. Lyon: Chronique Sociale

De Certeau, M. (1990). L'invention au quotidien. Paris: Folio

Detienne, M.; Vernant, J.P. (1974). Les ruses de l'intelligence. Paris: Champs essais

Filliettaz, L; Bronckart, J.P. (2005). L'analyse des actions et des discours en situation de travail. Concepts, méthodes et applications. Louvain-la-Neuve: Peeters

Goffman, E. (1973). La mise en scène de la vie quotidienne. Paris: Ed. de Minuit

Goffman, E. (1974). Les relations en public. Paris: Ed. de Minuit

Jorro, A. (2006). L'agir professionnel de l'enseignant. Conférence au séminaire de recherche. Paris: CRF-Cnam.

Jorro, A.; Quesnel, M.J.; Al Khatib, J; Ramsamy-Prat, P. (2016). Professional gestures. A museum educator at work. (under review). Social science information. Sage Publications.

Kerbrat-Orecchioni, C. (2005). Le discours en interaction. Paris: Armand Colin

Lave, J.; Wenger, E. (1999). Situated learning. Legitimate peripheral participation. Cambridge: CUP

Littlejohn, A.; Milligan, C.; Fontana, R.; Margaryan, A. (2016) Professional learning through everyday work: how finance professionals self-regulate their learning. Vocations and Learning. Springer (9), 207-226. DOI 10.1007/s12186015-9144-1.

Mayen, P. (2002). Le rôle des autres dans le développement de l'expérience. Education Permanente. (151), 87-107 
Mauss, M. (1950). Anthropologie et sociologie. Paris: PUF

Mondada, L. (2005). L'exploitation située de ressources langagières et multimodales dans la conception collective d'une exposition. P135-154. Dans Filliettaz, Bronckart (Eds.) L'analyse des actions et des discours en situation de travail. Concepts, méthodes et applications. Louvain-la-Neuve: Peeters

Mondada, L. (2016). A professional touch. International Conference on Gesture Studies. Paris: La Sorbonne

Ramsamy-Prat, P. (2014). Seniors et juniors: échanges interindividuels et transmission des savoirs. Dans Cros, Meyer (Eds). ) La communication interpersonnelle en formation. Usages, effets et enjeux. Lyon: Chronique Sociale

Ramsamy-Prat, P. (2015.) Le savoir relationnel du pharmacien. Scènes, discours et micro-actes professionnels. Thèse. Paris: Conservatoire National des Arts et Métiers, Cnam

Vermersch, P. (1994, 2011). L'entretien d'explicitation. Paris: ESF 